\title{
Preparation and Characterization of $\mathrm{k}$-Carrageenan Modified with Maleic Anhydride and Its Application in Films
}

\author{
Yuan Zhou ${ }^{1,+}$, Fu-Quan Chen ${ }^{1,2,3,4,+}$, Si Chen ${ }^{1,+}$, Qiong Xiao 1,2,3,4, Hui-Fen Weng 1,2,3,4, Qiu-Ming Yang ${ }^{1,2,3,4}$ \\ and An-Feng Xiao 1,2,3,4,* \\ 1 College of Food and Biological Engineering, Jimei University, Xiamen 361021, China; \\ 201811832012@jmu.edu.cn (Y.Z.); fqchenhy0109@jmu.edu.cn (F.-Q.C.); 201912951025@jmu.edu.cn (S.C.); \\ xiaoqiong129@jmu.edu.cn (Q.X.); 201572000057@jmu.edu.cn (H.-F.W.); yangqm@jmu.edu.cn (Q.-M.Y.) \\ 2 National R\&D Center for Red Alga Processing Technology, Xiamen 361021, China \\ 3 Fujian Provincial Engineering Technology Research Center of Marine Functional Food, Xiamen 361021, China \\ 4 Xiamen Key Laboratory of Marine Functional Food, Xiamen 361021, China \\ * Correspondence: xxaaffeng@jmu.edu.cn; Tel.: +86-592-6180-075 \\ + These authors contributed equally to this paper.
}

Citation: Zhou, Y.; Chen, F.-Q.; Chen, S.; Xiao, Q.; Weng, H.-F.; Yang, Q.-M.; Xiao, A.-F. Preparation and Characterization of $\mathrm{k}$-Carrageenan Modified with Maleic Anhydride and Its Application in Films. Mar. Drugs 2021, 19, 486. https://doi.org/ $10.3390 /$ md19090486

Academic Editor: Hitoshi Sashiwa

Received: 8 August 2021

Accepted: 25 August 2021

Published: 26 August 2021

Publisher's Note: MDPI stays neutral with regard to jurisdictional claims in published maps and institutional affiliations.

Copyright: (c) 2021 by the authors. Licensee MDPI, Basel, Switzerland. This article is an open access article distributed under the terms and conditions of the Creative Commons Attribution (CC BY) license (https:// creativecommons.org/licenses/by/ $4.0 /)$.

\begin{abstract}
In this work, the physicochemical properties of maleic anhydride (MAH)-modified $\mathrm{k}$-carrageenan ( $\mathrm{kCar}$ ) $(\mathrm{MC})$ were characterized and compared with those of native $\mathrm{k}$-carrageenan (NC). The Fourier transform infrared spectrum of MC exhibited that $\mathrm{kCar}$ was successfully modified. Thermogravimetric analysis indicated that the thermal stability of MC was decreased. When the degree of substitution was 0.032 , MC exhibited a low gel strength $\left(759 \mathrm{~g} / \mathrm{cm}^{2}\right)$, gelling temperature $\left(33.3^{\circ} \mathrm{C}\right)$, and dehydration rate $(60.3 \%)$. Given the excellent film-forming ability of $\mathrm{\kappa Car}, \mathrm{MC}$ films were then prepared and were found to have better mechanical and barrier properties (UV and water) than NC films. With regard to optical properties, MC films could completely absorb UV light in the range of 200-236 nm. The water contact angle of MC films was higher than that of NC films. Moreover, the elongation at break increased from $26.9 \%$ to $163 \%$. These physicochemical property changes imply that MC can be employed in polysaccharide-based films.
\end{abstract}

Keywords: K-carrageenan; maleic anhydride; modification; physicochemical property; film

\section{Introduction}

Carrageenan is a naturally linear polysaccharide that consists of alternating 3-linked $\beta$ D-galactopyranose and 4-linked $\alpha$-D-galactopyranose or 4-linked 3,6-anhydro- $\alpha$-D-glactopyranose, forming the disaccharide repeating unit of carrageenan [1]. As a type of sulfated polysaccharide, carrageenan can be categorized into $\mathrm{k}$ - (kappa), l- (iota), and $\lambda$ - (lambda) types according to the presence of the 3,6-anhydro-bridge on the 4-linked-galactose residue and the position and number of sulphate groups [2]. Given its gelling, thickening, emulsification, stability, and non-toxicity properties, $\mathrm{\kappa}$-carrageenan ( $\mathrm{kCar}$ ) is widely used in food and commodity industries [3], such as to thicken ice cream and milk drinks or as an emulsifier and stabilizer in toothpaste, cosmetic creams, and shampoos.

However, the use of ${ }$ Car processed by traditional methods is limited because of its disadvantages, such as high gel strength, easy shrinkage, and high melting temperature. For instance, the high gel strength of ${ }$ Car reduces the fluff and taste of pastry and steamed bread and increases the solidification of shampoo and toothpaste [4]. In many cases, the water retention of ${ }_{\mathrm{k}}$ Car might be below the required value. A gel with high water retention has good water holding stability and soft gel properties, thus endowing the product with stable tissue morphology and soft elastic characteristics [5]. Sinthsamran et al. [6] found that the high water holding capacity of $\kappa$ Car could prevent free water precipitation in meat products for preservation at a certain period. Moreover, its low melting and gelling temperature allows carrageenan to be combined with thermosensitive substances and thus 
save energy. Hence, different modification methods have been developed to modulate the physicochemical characteristics of $\kappa$ Car and thus improve its quality or expand its applications. Savoji and Pourjavadi [7] investigated a novel superabsorbent hydrogel based on $\mathrm{kCar}$ and polyacrylonitrile. A super swelling hydrogel with a water absorption capacity of up to $3260 \mathrm{~g} / \mathrm{g}$ (water/dry hydrogel powder) was obtained under optimized conditions. Papageorgiou et al. [8] studied novel isocyanate-modified carrageenan polymers as sorbent materials.

Maleic anhydride (MAH) is an important unsaturated organic acid anhydride with a strong oxidation property and can esterify hydroxyl compounds with high steric hindrance [9]. MAH-esterified starch, which was produced by using corn starch as the material and MAH as the esterifying agent via a dry method, could increase the length of the starch side chain and consequently enhance thermoplastic characteristics [10]. The modification of $\mathrm{kCar}$ with MAH has been reported [11,12]. However, reports on the modification of $\kappa \mathrm{Car}$ with MAH only and focusing on its physicochemical properties, such as gelling and thermal properties, are almost limited (to the best of the authors' knowledge). We hypothesize that $\mathrm{MAH}$ can replace one of the $\mathrm{kCar}$ hydroxyl groups and be grafted onto its structural unit. In consideration of the $\mathrm{kCar}$ gelation mechanism [13], introducing MAH groups to KCar molecules would form "kinks" and repulsive groups in molecular chains, reduce the binding force, and prevent the synthesis of double helix chains, thus weakening the gel strength of ${ }_{\mathrm{K} C a r}$ [14]. Inserting a bulky MAH group may reduce the interaction of adjacent $\mathrm{kCar}$ chains and promote discontinuity in the hydrogen bonding. Incorporating bulky groups on the $\mathrm{kCar}$ chains may also increase the ability of gels to retain water, thereby enhancing the water holding capacity [15]. The side chain length and the molecular chain spacing of $\mathrm{kCar}$ will also increase [16], whereas the intermolecular force will decrease, thus reducing the gelling temperature. These studies indicate that MAH modification transforms $\mathrm{kCar}$ as a new feature hydrocolloid with low gel strength and gelling temperature but high water holding capacity.

As a biodegradable polysaccharide, $\mathrm{kCar}$ has excellent film-forming features $[17,18]$. However, similar to most polysaccharide-based films, plain $\mathrm{kCar}$ films have some limitations due to their inherent hydrophilic nature that negatively affects their mechanical and water barrier properties as compared with normal synthetic polymers [19]. Numerous physical and chemical techniques have been developed to obtain desirable film properties. Blending with polymers [20], reinforcing with nanomaterials [21], or layering with other polymer films [22] can remarkably enhance the film properties of carrageenans.

In this study, the effects of MAH on the characteristics of $\mathrm{kCar}$ films were evaluated to expand the application of $\mathrm{kCar}$ in polysaccharide-based films. MAH-modified $\mathrm{kCar}$ was successfully prepared and films based on the mixed MAH-modified $\mathrm{kCar} /$ glycerol were prepared via solution casting. The major factors affecting MAH modification and the physicochemical properties of MC were studied. The microstructure, optical properties, mechanical properties, and water affinity of these modified $\kappa$ Car films were also determined and compared with those of native $k$ Car films. In conclusion, the chemical modification of $\kappa \mathrm{Car}$ with $\mathrm{MAH}$ is an effective and promising pathway to endow $\mathrm{\kappa}$ Car with new properties and consequently improve the features of $\mathrm{kCar}^{\mathrm{b}} \mathrm{based}$ films.

\section{Results and Discussion}

\subsection{Optimization of Reaction Conditions for MC Synthesis}

MAH forms maleic acid and esters when dissolved in water and ethanol, respectively, thus creating a mixture in the reaction [23]. Previous studies mostly focused on the reaction of MAH with starch and rarely on the reaction of MAH with kCar. Zuo et al. [10] reported that MAH modification for starch occurs mainly in the amorphous region of the granule with the maximum degree of substitution (DS) of 0.3386 . The availability of $-\mathrm{OH}$ groups at $\mathrm{C}-2, \mathrm{C}-3$, and $\mathrm{C}-6$ (glucose unit, $\mathrm{Mw}$ 162) renders native starch reactive for substitution [24]. $\kappa C$ ar consists of alternating $(1 \rightarrow 3)-\beta$-D-galactose-4-sulfate and $(1 \rightarrow 4)$ 3,6 -anhydro- $\alpha$-D-galactose residues joined in a linear chain, in which the available -OH 
groups possess different reactivities for esterification [1]. Similar to starch, $\mathrm{kCar}$ has an extremely high water-absorbing capacity to react easily. However, $k$ Car has no crystalline region, which means that the water-absorbing capacity of $\mathrm{kCar}$ is higher than that of starch. Therefore, $\mathrm{kCar}$ has less reactivity than starch, leading to a lower DS. Gel strength is also an important index for $\mathrm{kCar}$. High gel strength is not always the most desirable quality for $\kappa$ Car. However, low strength bestows the product with a stable structure and soft elastic characteristics. KCar with low gel strength has potential uses in liquid food, spread food, soft-texture confectionery, fat replacers, and new industrial applications, and can also serve as a cryoprotectant to minimize the damage of freezing-thawing $[25,26]$. Thus, the effects of five factors on the DS and gel strength of MC were studied.

The effects of MAH concentration on DS and gel strength are illustrated in Figure 1a. Each $\kappa^{C}$ ar structural unit has three $-\mathrm{OH}$ groups and one sulphate group. MAH could replace one of the hydroxyl groups and be grafted onto the $\kappa$ Car structural unit [11]. The concentration of MAH possibly affected the diffusion of MAH into the $\mathrm{kCar}$ molecules. When the MAH concentration was increased from $2 \%$ to $8 \%$, the available MAH groups around the $\mathrm{kCar}$ molecule increased, leading to an increase in DS. However, an overly high concentration of MAH was unfavorable for the substitution. In order to maintain the reaction $\mathrm{pH}$ constant, it was necessary to add vast quantities of alkali, which resulted in the swelling of $k$ Car and difficulty to agitate the reaction system, thus reducing the DS. Moreover, gel strength was negatively correlated with DS. This result may be attributed to the introduction of substituents that broke and loosened up the hydrogen bonding between кCar molecules [27], which prevented the synthesis of double helix chains. Thus, $8 \%$ was selected as the optimal MAH concentration in the subsequent experiments.
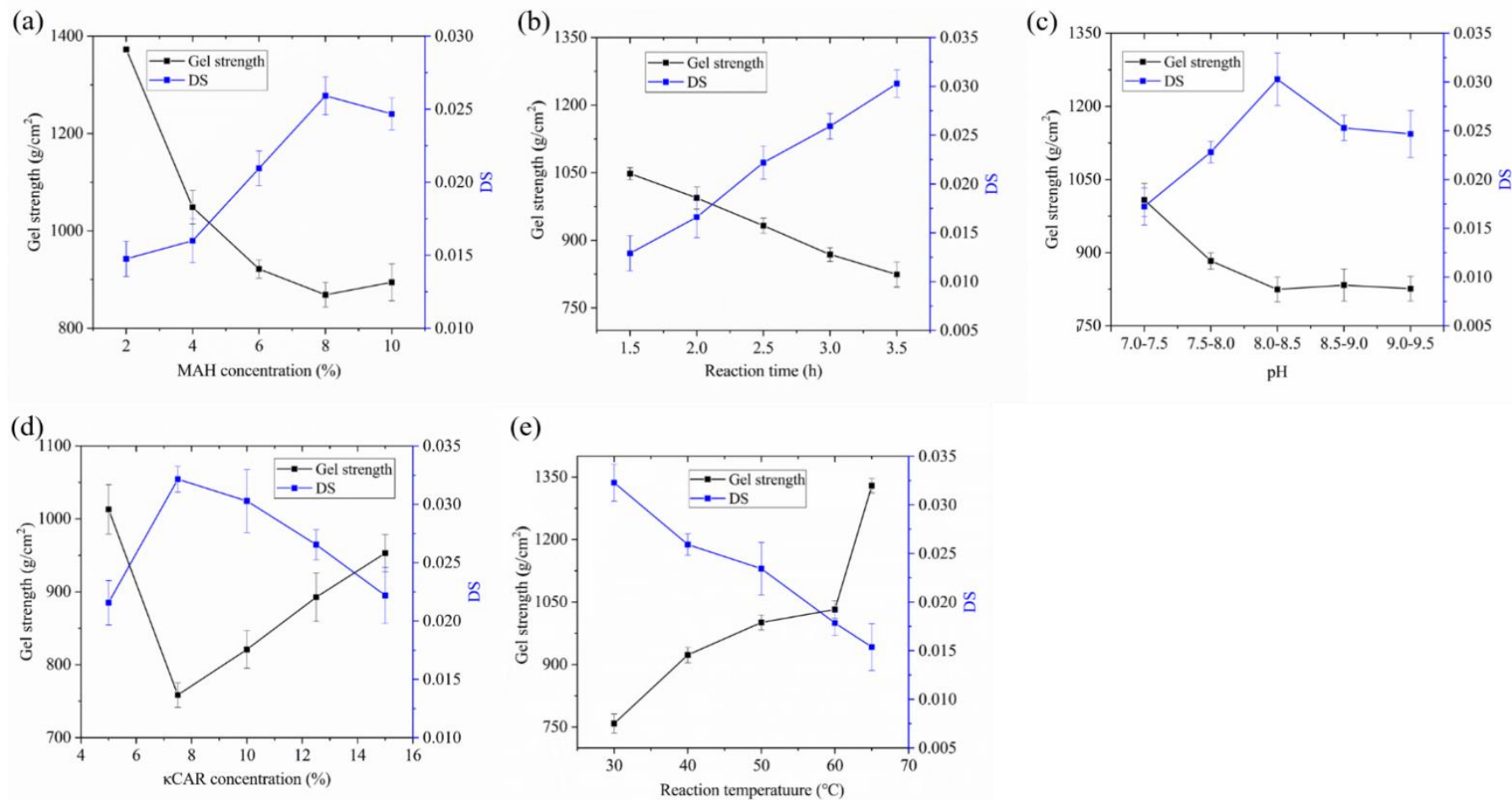

Figure 1. Effects of reaction conditions on modification. (a) Effect of MAH concentration on modification: reaction time $3.5 \mathrm{~h}, \mathrm{pH} 8-8.5, \mathrm{kCar}$ concentration $7.5 \%$, and reaction temperature $30{ }^{\circ} \mathrm{C}$; (b) Effect of reaction time on modification: $\mathrm{MAH}$ concentration $8 \%, \mathrm{pH} 8-8.5, \mathrm{kCar}$ concentration $7.5 \%$, and reaction temperature $30{ }^{\circ} \mathrm{C}$; (c) Effect of $\mathrm{pH}$ on modification: MAH concentration $8 \%$, reaction time $3.5 \mathrm{~h}$, $\mathrm{kCar}$ concentration $7.5 \%$, and reaction temperature $30^{\circ} \mathrm{C}$; (d) Effect of $\mathrm{kCar}$ concentration on modification: MAH concentration $8 \%$, reaction time $3.5 \mathrm{~h}, \mathrm{pH} 8-8.5$, and reaction temperature $30{ }^{\circ} \mathrm{C}$; (e) Effect of reaction temperature on modification: MAH concentration $8 \%$, reaction time $3.5 \mathrm{~h}, \mathrm{pH} 8-8.5$, and $\mathrm{kCar}$ concentration $7.5 \%$. The reaction was carried out by changing one parameter in each case but keeping the other 4 parameters constant (pooled data from three experiments are presented as means \pm standard deviation of the mean $(n=3)$ ). 
According to Figure $1 \mathrm{~b}$, the DS of MC was steadily increased when the reaction time was prolonged from $1.5 \mathrm{~h}$ to $3.5 \mathrm{~h}$. This result could be interpreted by the increased contact and collision between the MAH and $\mathrm{kCar}$ with the prolonged reaction time, which was similar to the report described previously [28]. In the present study, the gel strength was decreased with prolonged reaction time because the introduction of esterification groups to $\mathrm{kCar}$ molecules can reduce the interaction of adjacent $\mathrm{kCar}$ chains and promote discontinuity in the hydrogen bonding [14]. In addition, the disruption of hydrogen bonds also facilitates water penetration to the interior of the particles [29]. Thus, the $\mathrm{kCar}$ being in the lye for a long period of time might damage its structure and reduce its gel strength.

Tailoring the $\mathrm{pH}$ of the reaction system is important for the modification of $\mathrm{kCar}$, and during modification, $\mathrm{NaOH}$ was used for keeping the $\mathrm{pH}$ constant. Figure 1c exhibits the effect of the $\mathrm{pH}$ of the reaction system on the modification of $\mathrm{kCar}$. DS rapidly increased when the $\mathrm{pH}$ was increased from 7.0 to 8.5. This finding may be related to the fact that effective alkalinity could promote the nucleophilicity of the hydroxyl group and swell the $\kappa$ Car particles, resulting in higher substitution; while with a further increase in $\mathrm{NaOH}$ amount, the hydrolysis of MAH and MC was accelerated, resulting in a decrease in DS [16]. The gel strength was not increased with the decreasing DS, indicating that this parameter was highly affected by alkalinity. Therefore, the appropriate reaction $\mathrm{pH}$ was 8-8.5.

To determine the influence of $\kappa$ Car concentration, the experiment was performed, and the result is shown in Figure 1d. The DS reached the maximum when the $\mathrm{KCar}^{\mathrm{C}}$ concentration was increased to $7.5 \%(w / v)$. A continuous increase in $\mathrm{kCar}$ concentration resulted in a decrease in DS. This result was due to the swelling of $k$ Car, which was difficult to agitate in the reaction system. Ruan et al. [30] also found a similar result of octenyl succinic anhydride modified starch. Therefore, it was possible to obtain MC with a higher DS under the concentration of $7.5 \% \mathrm{k}$ Car.

The effect of reaction temperature on the modification of $\mathrm{KCar}$ is illustrated in Figure 1e. With the increase in reaction temperature from $30^{\circ} \mathrm{C}$ to $65^{\circ} \mathrm{C}$, the DS gradually decreased from 0.032 to 0.015 . The reactant activity and reaction rate decreased with the increasing temperature because the esterification was exothermic. Thus, MC with a DS of 0.032 and gel strength of $759 \mathrm{~g} / \mathrm{cm}^{2}$ was obtained when the reaction temperature was $30^{\circ} \mathrm{C}$.

\subsection{Characterization of $M C$}

\subsubsection{Fourier Transform Infrared (FT-IR) Analysis}

FT-IR was used to investigate the changes in $\mathrm{kCar}$ after modification, as shown in Figure 2a. The characteristic absorption peaks of $\kappa^{-C a r}$ appearing at 845 and $930 \mathrm{~cm}^{-1}$ contributed to the $\mathrm{C}-\mathrm{H}$ bending of substituted D-galactose-4-sulfate and the $\mathrm{C}-\mathrm{O}$ bond of 3,6-anhydro-D-galactose (3,6-AG), respectively [12]. The extremely broad band at approximately $3440 \mathrm{~cm}^{-1}$ corresponded to the vibration of the hydroxyl groups $(\mathrm{O}-\mathrm{H})$. In addition, the band at $1250 \mathrm{~cm}^{-1}$ was characteristic of $\mathrm{S}=\mathrm{O}$ of sulfate esters. Compared with NC, MC (DS = 0.032) exhibited new peaks at 1576 and $1734 \mathrm{~cm}^{-1}$. The peak at $1576 \mathrm{~cm}^{-1}$ corresponded to the asymmetric stretching vibration of the carboxylate ( $\mathrm{RCOO}-$ ), whereas the peak at $1734 \mathrm{~cm}^{-1}$ suggested the formation of ester carbonyl groups $(\mathrm{C}=\mathrm{O})$ between the $\mathrm{kCar}$ and MAH [31]. These two additional peaks of MC confirmed that $\mathrm{kCar}$ was successfully modified by MAH, which was in agreement with a previous study [11]. 
(a)

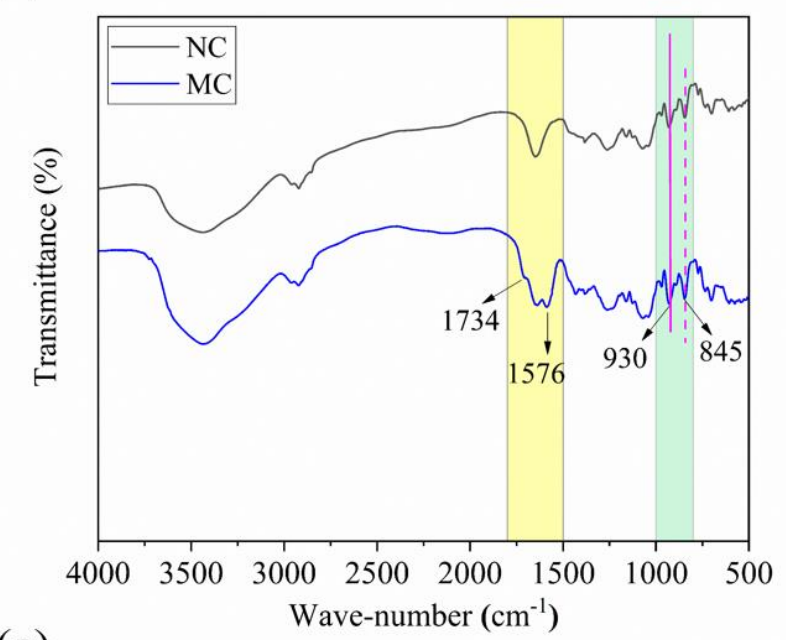

(c)

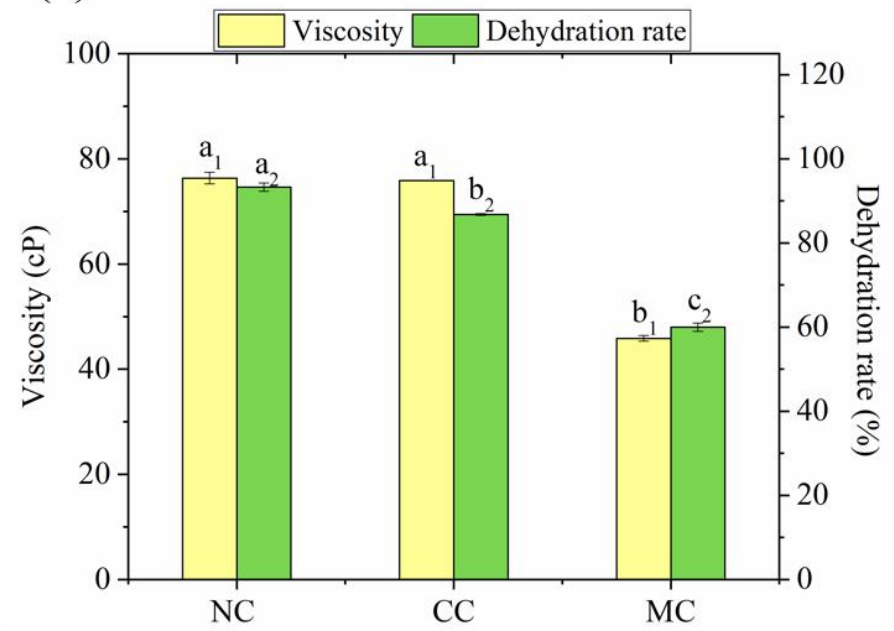

(b)

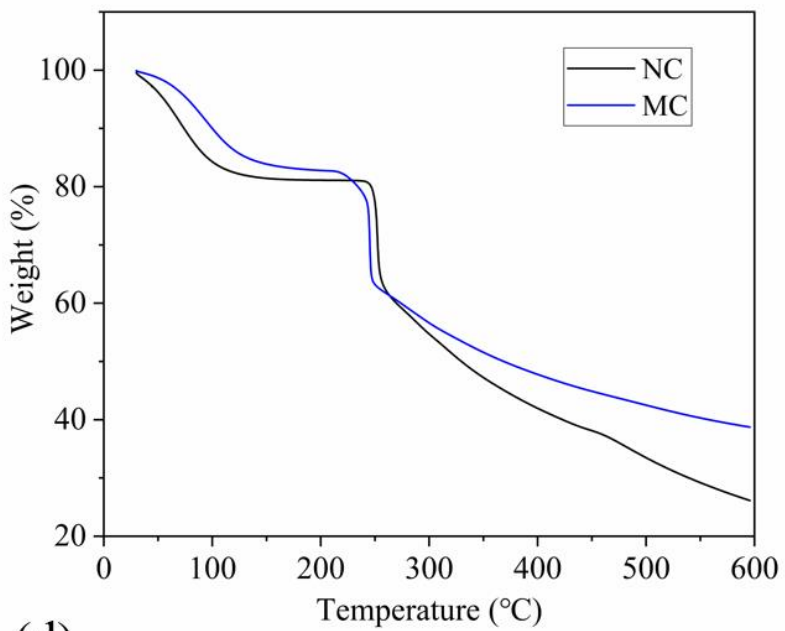

(d)

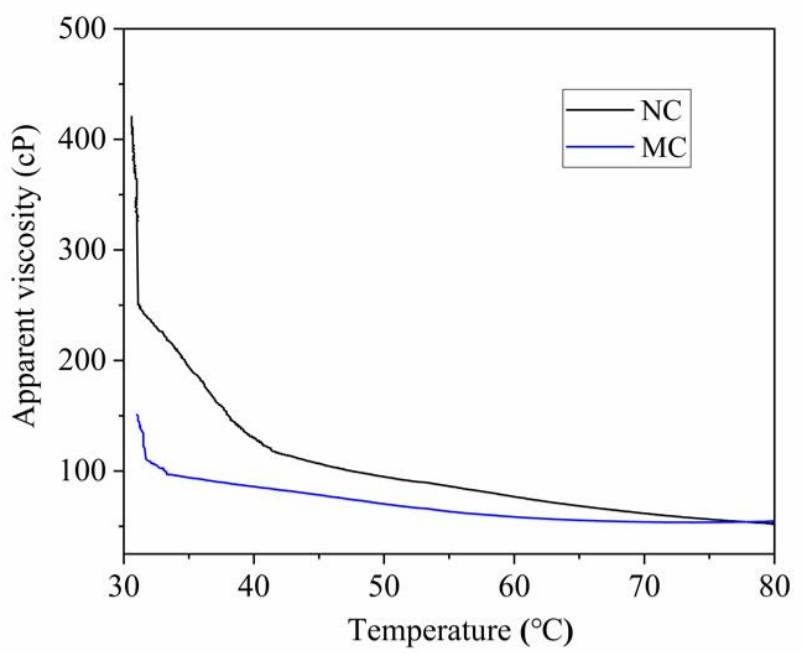

Figure 2. (a) FT-IR spectra; (b) TGA spectra of NC and MC; (c) viscosity and water-holding capacity of $\mathrm{kCar}$ samples; (d) viscosity-temperature curves of $\mathrm{NC}$ and $\mathrm{MC}$; CC: control $\kappa \mathrm{Car} . \mathrm{a}_{1}, \mathrm{~b}_{1}$ on the bar graph indicate significant differences in viscosity $(p<0.05)$ and $\mathrm{a}_{2}, \mathrm{~b}_{2}, \mathrm{c}_{2}$ indicate significant differences in dehydration rate $(p<0.05)$ in Figure $2 \mathrm{c}$.

\subsubsection{Thermogravimetric Analysis (TGA)}

Figure $2 b$ shows the TGA profiles of NC and MC. Weight loss in NC and MC occurred in three main temperature phases. NC and MC (DS $=0.032)$ partially lost weight in the temperature range of $30-160^{\circ} \mathrm{C}$ as a result of free water reduction. Given the same moisture contents of NC and MC after drying, their water holding capacity could be defined by their water loss rate. The water loss rate of $\mathrm{MC}$ was lower than that of NC, probably indicating that $\mathrm{MC}$ had higher water holding capacity than NC. At the temperature range of $200-250{ }^{\circ} \mathrm{C}$, NC and MC showed a sharp mass loss of $20 \%$, suggesting the rapid decomposition of $\mathrm{kCar}$ at this stage. Moreover, the initial degradation temperature of the MC was lower than that of the $\mathrm{NC}$, indicating that the introduction of the MAH group may negatively affect the thermal stability of KCar. A similar result was reported by Chen et al. [32], who found that the thermal stability of agar also declined after chemical modification. When the temperature was increased up to $600{ }^{\circ} \mathrm{C}$, the decomposition then proceeded slowly. The higher remaining residue of $\mathrm{MC}$ than that of $\mathrm{NC}$ could be attributed to the introduction of MAH groups. 


\subsection{Physicochemical Properties}

\subsubsection{Viscosity and Water Holding Capacity}

As shown in Figure 2c, the viscosity of MC (DS $=0.032$ ) was $39.9 \%$ lower than that of $\mathrm{NC}$, and this value was conducive to the preparation of MC film-forming solution. A similar pattern regarding viscosity was observed in starch esterified by octenyl succinic anhydride [33]. The decreased viscosity of MC could be due to the breakage of hydrogen bonds and the weakening of intermolecular forces of carrageenan after the introduction of MAH groups. In addition, the introduced branched chains may hinder the intertwining of the molecular chains of carrageenan, resulting in the reduced viscosity of MC. Furthermore, the partial hydrolysis of carrageenan chains under alkaline esterification may also decrease the viscosity [34].

Compared with that from NC, the water released from MC (DS $=0.032)$ was $33.0 \%$ lower after freezing-thawing, as shown in Figure 2c. Therefore, MC had better water holding capacity than $\mathrm{NC}$, and this finding was consistent with the TGA results. Several factors may account for this phenomenon. On the one hand, the double helixes of carrageenan were reduced after MAH esterification, thus exposing many hydroxyl groups that formed hydrogen bonds with water and improved the water holding capacity. On the other hand, the branching structure of MC increased the side chain length and steric hindrance of the molecular chain and consequently the water holding capacity. The ability of MC to retain large amounts of water allows for stabilized suspensions in emulsions and provides great resistance to deformation; this feature has some potential applications in biomedicine, refrigeration, the food industry, and cosmetics [35]. Meindrawan et al. [36] reported that nanocomposite coatings based on $\mathrm{kCar}$ and $\mathrm{ZnO}$ nanoparticles could maintain the storage quality of mango by decreasing water permeability and increasing the water holding capacity.

The apparent viscosity of MC (DS $=0.032)$ solution was basically lower than that of $\mathrm{NC}$ at the same temperature, as shown in Figure 2d. Initially, the apparent viscosity of the samples was basically stable from $70{ }^{\circ} \mathrm{C}$ to $80^{\circ} \mathrm{C}$. Thereafter, the increase in viscosity became apparent as the temperature was lowered. When the temperatures of $\mathrm{NC}$ and MC were further reduced to $40{ }^{\circ} \mathrm{C}$ and $33^{\circ} \mathrm{C}$, their apparent viscosities started to increase sharply with the decrease in temperature, indicating that the $\mathrm{kCar}$ molecules started to form gels. Therefore, the gelling temperature of MC was lower than that of NC.

\subsubsection{Other Properties}

The physical properties of the $\mathrm{kCar}$ samples are illustrated in Table 1 . It could be seen that the MAH modification significantly influenced the gel strength and the 3,6-AG

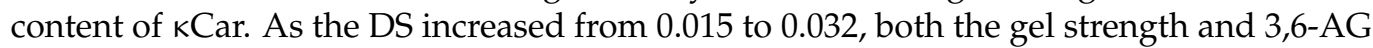
of MC decreased. Among them, the decreased gel strength of MC may be attributed to the introduction of MAH groups and electrostatic repulsion from the carboxylate groups, thereby hindering the aggregation of helical conformation [32]. The reduced 3,6-AG content in MC was possibly caused by the degradation of $\kappa$ Car by MAH. In addition, the sulfate content of MC was not significantly changed compared to that of NC.

Table 1. Other physicochemical properties of $\mathrm{kCar}$.

\begin{tabular}{ccccc}
\hline Physicochemical Properties & NC & CC & MC/DS = 0.015 & MC/DS = 0.032 \\
\hline Gel strength $\left(\mathrm{g} / \mathrm{cm}^{2}\right)$ & $1441 \pm 20^{\mathrm{a}}$ & $1432 \pm 19^{\mathrm{a}}$ & $1329 \pm 17^{\mathrm{b}}$ & $759 \pm 23^{\mathrm{c}}$ \\
3,6-AG content $(\%)$ & $22.5 \pm 0.3^{\mathrm{a}}$ & $22.4 \pm 0.1^{\mathrm{a}}$ & $18.8 \pm 0.1^{\mathrm{b}}$ & $17.1 \pm 1.3^{\mathrm{b}}$ \\
Sulfate content $(\%)$ & $25.7 \pm 1.7^{\mathrm{a}}$ & $23.2 \pm 3.6^{\mathrm{a}}$ & $22.5 \pm 1.7^{\mathrm{a}}$ & $22.1 \pm 1.1^{\mathrm{a}}$ \\
Transparency $(\%)$ & $81.9 \pm 0.1^{\mathrm{d}}$ & $86.9 \pm 0.1^{\mathrm{c}}$ & $87.6 \pm 0.0^{\mathrm{b}}$ & $91.6 \pm 0.1^{\mathrm{a}}$ \\
Whiteness $(\%)$ & $57.3 \pm 0.2^{\mathrm{b}}$ & $54.3 \pm 0.2^{\mathrm{d}}$ & $58.5 \pm 0.2^{\mathrm{a}}$ & $56.9^{\mathrm{a}} \pm 0.1^{\mathrm{c}}$ \\
Dissolving temperature $\left({ }^{\circ} \mathrm{C}\right)$ & $96.6 \pm 0.1^{\mathrm{a}}$ & $95.1 \pm 2.6^{\mathrm{a}}$ & $93.1 \pm 2.6^{\mathrm{a}}$ & $93.1 \pm 0.1^{\mathrm{a}}$ \\
Gelling temperature $\left({ }^{\circ} \mathrm{C}\right)$ & $40.9 \pm 0.2^{\mathrm{a}}$ & $39.4 \pm 0.9^{\mathrm{b}}$ & $35.8 \pm 0.4^{\mathrm{c}}$ & $33.3 \pm 0.4^{\mathrm{d}}$ \\
Melting temperature $\left({ }^{\circ} \mathrm{C}\right)$ & $55.7 \pm 0.1^{\mathrm{a}}$ & $54.6 \pm 0.4^{\mathrm{b}}$ & $54.0 \pm 0.9^{\mathrm{b}}$ & $50.4 \pm 0.0^{\mathrm{c}}$ \\
\hline
\end{tabular}

Values are mean \pm standard deviation. Different lowercase superscripts within the same row indicate significant differences $(p<0.05)$. CC: control $k$ Car. 
Variations in transparency occur due to the penetration, refraction, and reflection of light at different intensities when irradiating different solutions. Transparency affects product quality, properties, and uses. Carrageenan with high transparency is widely used. Highly transparent carrageenan film for observational experiments can be prepared by mixing with glycerol. As shown in Table 1, the transparency of MC increased remarkably from $81.9 \%$ to $91.6 \%$ by $11.8 \%$ with the increase in DS. The results could be explained as follows: the introduction of MAH groups prevented the carrageenan molecules from binding to each other and the formation of the double helix structure, thus allowing light to penetrate easily [37].

The dissolution of carrageenan in water can be divided into two steps: first, carrageenan swells and partially hydrates, and the polymer chain is then broken and dissolved [13]. In the present research, the MC powder could be dissolved in water at $93.1^{\circ} \mathrm{C}$ when the DS was 0.032 . Esterification can weaken the internal hydrogen bond of carrageenan molecules and easily unite the polymerization chains [32]. Moreover, the degradation of carrageenan by MAH can destroy the partial molecular structure of carrageenan. Therefore, carrageenan could be dissolved at a low temperature, thus creating a favorable condition for the preparation of film-forming solution.

The gelling temperature of $\mathrm{MC}(\mathrm{DS}=0.032)$ was $7.6^{\circ} \mathrm{C}$ lower than that of $\mathrm{NC}$, and this value was consistent with the previous report [38] and the results of viscosity temperature curve analysis. Gelation occurs when hot solutions are cooled and involves coil-helix transition, followed by helix aggregation [39]. The coil to double helix transition is the key step for gelation. The introduction of the large MAH group may weaken the hydrogen bond and prevent the formation of a double helix structure. The $k$ Car double helix broke prematurely during heating because of the weak bonds and intermolecular forces; thus, MC began to melt at a low temperature. The low melting temperature was ascribed to the low energy required to break down the network, indicating that the gels of $\mathrm{MC}$ were less stable with loose aggregation than those of NC [40,41]. The decrease in dissolving, gelling, and melting temperatures allows for the joint application of temperature-sensitive substances and $\mathrm{kCar}$.

\subsection{Characterization and Properties of NC/MC Films}

\subsubsection{Morphology}

To investigate the microstructure of the NC and MC films, the morphology of the surface and cross-section of the films was observed, as shown in Figure 3. The NC film showed a smooth and compact surface (Figure $3 \mathrm{a}, \mathrm{b}$ ), but the MC film exhibited an obvious rough surface (Figure $3 \mathrm{~d}, \mathrm{e})$. The results indicated that the surface roughness of $\kappa$ Car-based films increased after modification with MAH. Moreover, cross-sectional SEM micrographs of NC and MC films are shown in Figure 3c,f, respectively. The cross-section images confirmed that the cross-section of the $\mathrm{kCar}-\mathrm{based}$ film changed from dense to porous after modification. All changes in the microstructure revealed that the modification reaction had taken place. Similar microstructural results have been reported for OSA-modified sweet potato starch film [42].

\subsubsection{Optical Properties}

The color parameters are integral to the appearance and consumer acceptance of packaged products [43]. The color of the NC and MC films was evaluated by using $L$ (whiteness and blackness), $a$ (redness and greenness), and $b$ (yellowness and blueness) values and $\Delta E$. As shown in Table 2, the NC and MC films presented negative values of $a$ and positive values of $b$, signifying their greenish yellow color. Compared with NC films, the MC films leaned toward yellow, as suggested by their higher $b$ values. Moreover, the values of $a$ and $\triangle E$ did not significantly differ between the NC and MC films. The $L$ value of MC films was comparative to that of NC films, implying that both have high transparency. These results could be attributed to the high transparency of NC and MC, which brightened the films. 

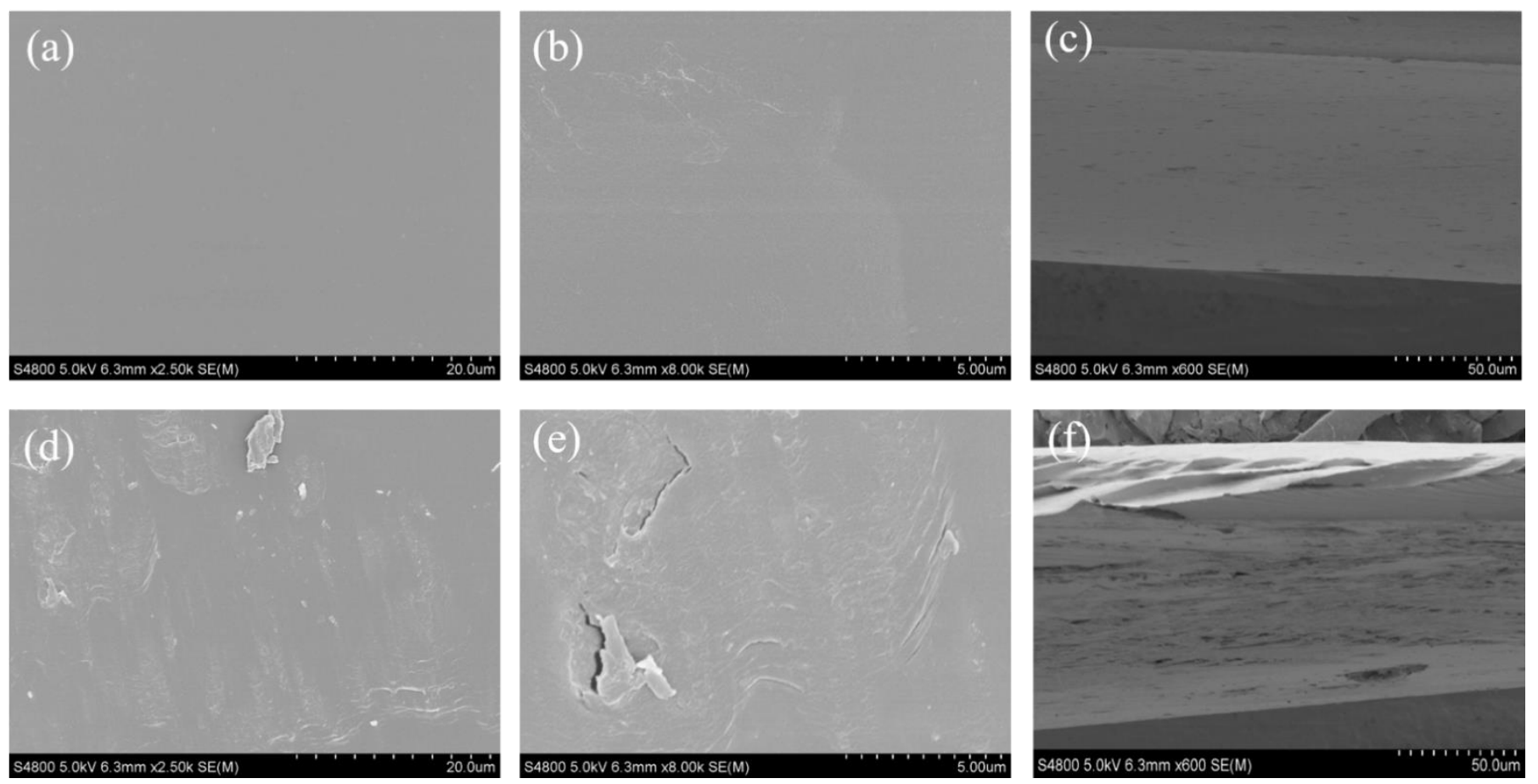

Figure 3. (a,b) SEM surface images of NC films magnified by $2500 \times$ and $8000 \times$, respectively; (c) SEM cross-section image of NC films; (d,e) SEM surface images of MC films magnified by $2500 \times$ and $8000 \times$, respectively; (f) SEM cross-section image of MC films.

Table 2. Color parameters of the films.

\begin{tabular}{ccccc}
\hline & $\boldsymbol{L}$ & $\boldsymbol{a}$ & $\boldsymbol{b}$ & $\boldsymbol{\Delta} \boldsymbol{E}$ \\
\hline NC film & $89.29 \pm 0.22^{\mathrm{a}}$ & $-0.92 \pm 0.06^{\mathrm{a}}$ & $2.74 \pm 0.08^{\mathrm{b}}$ & $2.89 \pm 0.20^{\mathrm{a}}$ \\
MC film & $89.51 \pm 0.25^{\mathrm{a}}$ & $-1.04 \pm 0.05^{\mathrm{a}}$ & $3.18 \pm 0.02^{\mathrm{a}}$ & $2.94 \pm 0.21^{\mathrm{a}}$ \\
\hline
\end{tabular}

Values are mean \pm standard deviation. Different lowercase superscripts within the same column indicate significant differences $(p<0.05)$.

Transmittance strongly affects film functionality due to its great effect on the appearance of packaged products [44]. Figure 4a shows the transmittance curves of the films. The transmittance of NC and MC films was high at above $80 \%$ in the visible light range of 400-800 nm. However, in the UV region of 200-400 nm, the transmittance of both films decreased to different degrees with the reduction in wavelength. Within the wavelength of 236-300 nm, the transmittance of the NC films decreased from $78 \%$ to $62 \%$, and that of the MC films decreased drastically from $81 \%$ to $0 \%$. These results showed that the MC films could completely absorb UV light in the range of 200-236 nm. This phenomenon could be attributed to the introduction of $\mathrm{MAH}$ groups, resulting in conjugated double bonds in the MC film. Lu et al. [45] found that the neat polyvinyl alcohol film has an extremely high transmittance in the whole UV-Vis light range. After disassembled polydopamine (PDA) was introduced into the film, the transmittance in UV and visible regions decreased seriously due to the conjugation effect of PDA. 


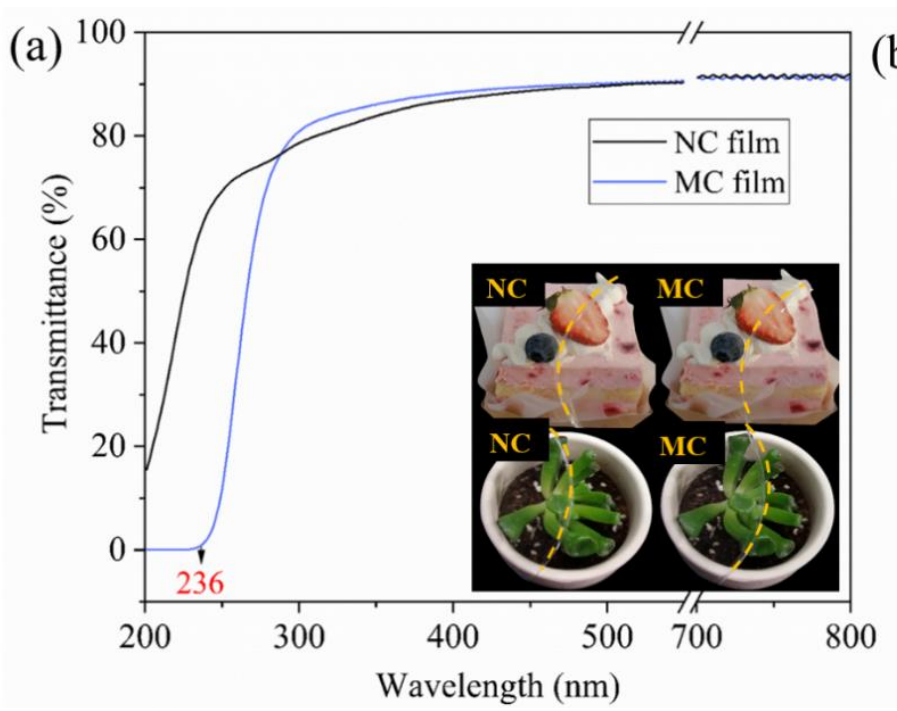

(b)

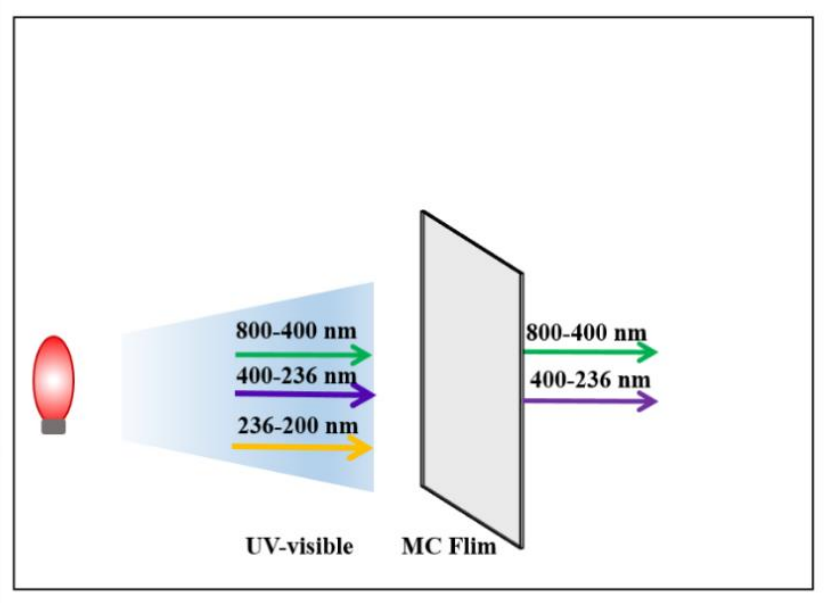

Figure 4. (a) Light transmittance of the films and (b) UV absorbability of the MC film.

\subsubsection{Mechanical and Water Affinity Properties}

The mechanical properties of films include tensile strength (TS) and elongation at break (EB), with the former elaborating the resistance of the film to elongation and the latter denoting the ductility of the film. Figure 5a shows the TS and EB of the NC and MC films. Compared with that of the NC films, the TS of the MC films decreased from $82.0 \mathrm{MPa}$ to $54.3 \mathrm{MPa}$, and the EB increased from $26.9 \%$ to $163 \%$. The decrease in TS in the MC films may be due to the substitution of hydroxyl groups in the chain of $\kappa^{C}$ ar, resulting in the reduction of intermolecular hydrogen bonds and the weakening of the polymerization ability of $\mathrm{kCar}$, which destroyed the integrity of the MC films. Li et al. [42] confirmed that the presence of octenyl groups weakened the molecular interactions within the film matrix and thus reduced the TS of octenyl succinated sweet potato starch film. Meanwhile, the reduction of intermolecular forces increased the mobility and deformation of carrageenan molecular chains, which in turn enhanced its flexibility and ductility and thereby increased the EB.

Moisture content, water vapor permeability (WVP), and water contact angle were used to determine the water resistance of the films. The effects of $\kappa$ Car modification on the water resistance of MC films are shown in Figure $5 \mathrm{~b}$. No significant differences $(p>0.05)$ in moisture content and WVP were noticed between the NC and MC films, indicating that «Car modification only had a slight effect on the moisture content and WVP of $\kappa$ Car films. The water contact angle reflects the hydrophilic/hydrophobic surface properties of the materials. In general, a material with hydrophobicity also has a high contact angle. As can be seen in Figure $5 c$, the contact angles of both MC films were higher than those of NC films as time increased. The contact angles of $\mathrm{MC}$ and $\mathrm{NC}$ films were kept at approximately $78^{\circ}$ and $30^{\circ}$, respectively. This revealed that the surface hydrophobicity of $\kappa$ Car-based films was improved after MAH modification, which could be related to the increased roughness of the MC films compared with that of the NC film, as shown in the SEM micrographs (Figure 3). In addition, the introduction of hydrophobic MAH molecules and the reduction of hydrophilic groups $(-\mathrm{OH})$ due to the covalent bonds formed between MAH molecules and $\kappa$ Car were other reasons for the increased surface hydrophobicity of MC films $[46,47]$. 
(a)

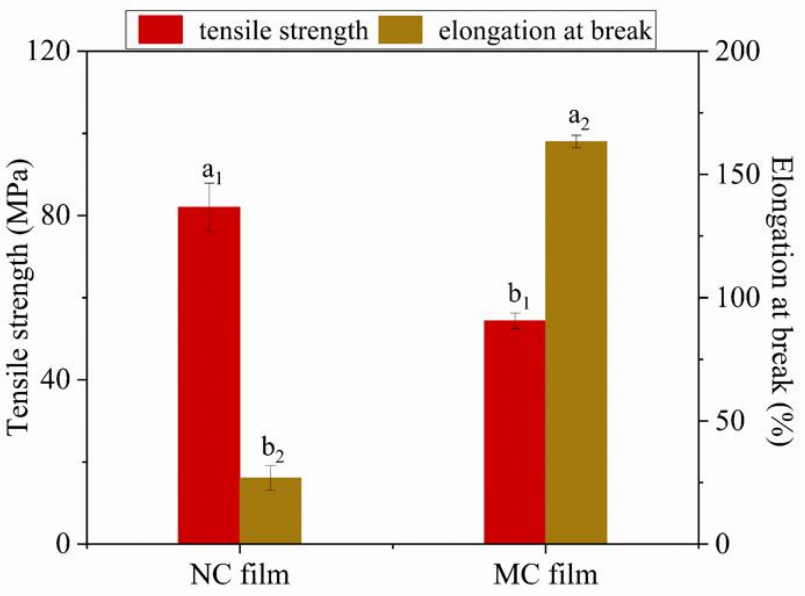

(b)

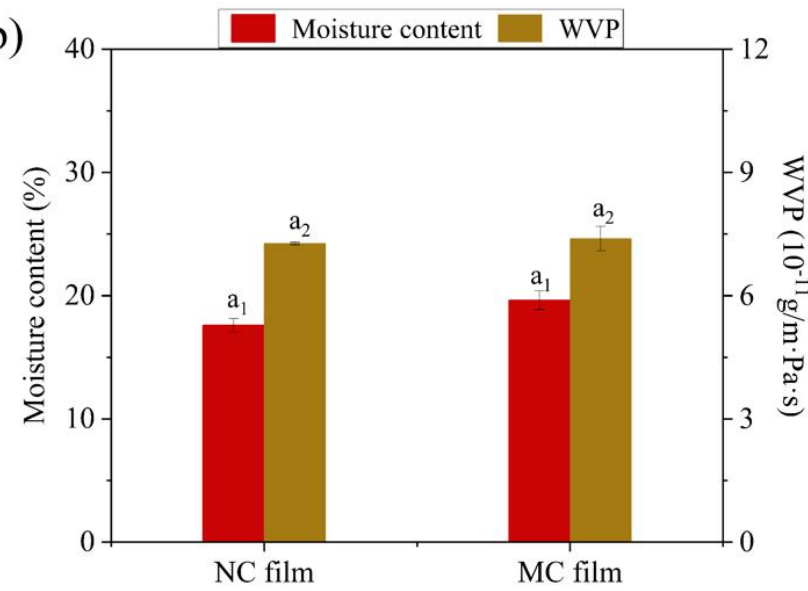

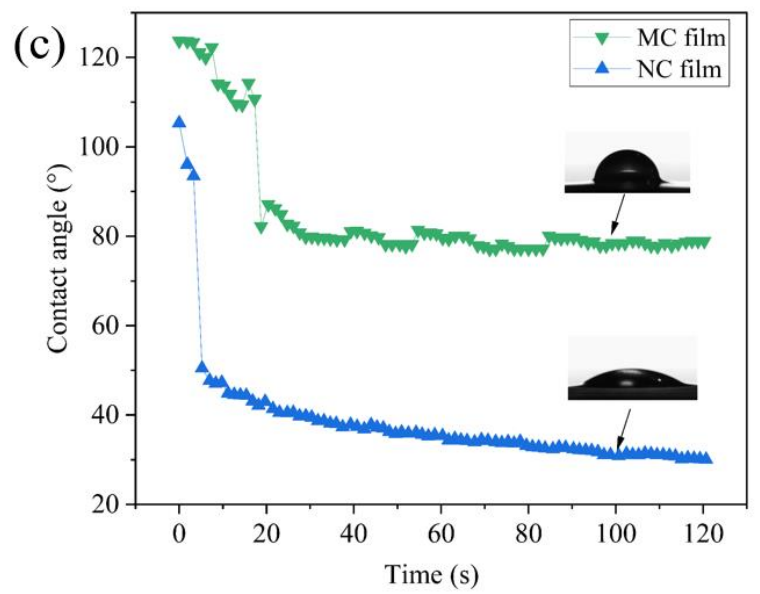

Figure 5. (a) Tensile strength and elongation at break; (b) moisture content and water vapor permeability; (c) contact angle curves along with time of the films. $\mathrm{a}_{1}, \mathrm{~b}_{1}$ indicate significant differences in tensile strength in Figure $5 \mathrm{a}(p<0.05)$; $\mathrm{a}_{2}, \mathrm{~b}_{2}$ indicate significant differences in elongation at break in Figure $5 \mathrm{a}(p<0.05) ; \mathrm{a}_{1}$ indicates no significant differences in moisture content in Figure $5 b(p>0.05) ; a_{2}$ indicates no significant differences in water vapor permeability in Figure $5 b(p>0.05)$.

\section{Materials and Methods}

\subsection{Materials}

Food-grade $k$ Car (gel strength $\geq 1300 \mathrm{~g} / \mathrm{cm}^{2}$, ash content $15-25 \%$, and moisture content $\leq 12 \%$ ) was obtained from Greenfresh (Fujian) Food Stuff Co., Ltd. (Fujian, China). MAH was purchased from Vertellus (Shanghai, China) Chemical Co., Ltd. (Shanghai, China). Sodium hydroxide, hydrochloric acid, anhydrous ethanol, isopropanol, glycerol, and sodium bromide were all of analytical grade and purchased from Sinopharm Chemical Reagent Co., Ltd. (Shanghai, China). All chemicals were used as received without further purification.

\subsection{Synthesis of $M C$}

MC was prepared using MAH according to a previous report with minor modifications [48]. Initially, different concentrations of $\kappa$ Car powder based on the volume of the reaction system $(w / v)$ were dispersed in $200 \mathrm{~mL}$ of ethanol solution $(80 \%)$ and magnetically stirred at different temperatures. Then, MAH dissolved in absolute alcohol with a ratio of 1:3 (MAH: absolute alcohol, $w / v$ ) was added dropwise to the previous mixture for $1 \mathrm{~h}$ and then continuously stirred for $0.5-2.5 \mathrm{~h}$. $\mathrm{pH}$ of the suspension was adjusted (7.0-9.5) by adding the alkaline solution $(1 \mathrm{M} \mathrm{NaOH})$. At the end of the reaction, the obtained mixture was washed three times with $80 \%$ ethanol and oven-dried overnight at $55^{\circ} \mathrm{C}$. 


\subsection{Determination of $D S$}

The DS of MC was measured by the method described earlier [49]. In brief, $1.0 \mathrm{~g}$ of sample was accurately weighed and soaked with $5 \mathrm{~mL}$ of isopropanol solution. The suspension was stirred for $30 \mathrm{~min}$ in $15 \mathrm{~mL}$ of $2.5 \mathrm{~mol} / \mathrm{L}$ hydrochloric acid-isopropanol solution. The mixture was added with $30 \mathrm{~mL}$ of $90 \%$ isopropanol solution and then stirred for another $10 \mathrm{~min}$. The residue was washed with $60 \%$ ethanol until no $\mathrm{Cl}^{-}$remained (as examined with silver nitrate solution), then dispersed in $100 \mathrm{~mL}$ of deionized water, and dissolved in a microwave oven for $3 \mathrm{~min}$. The solution was titrated with $0.02 \mathrm{M}$ sodium hydroxide using phenolphthalein as an indicator. Consumption volume was recorded. DS was calculated with the following equations:

$$
\begin{gathered}
\text { DS }=(0.385 \times \mathrm{A}) /(1-0.098 \times \mathrm{A}) \\
\mathrm{A}=(\mathrm{C} \times \mathrm{V}) / \mathrm{W}
\end{gathered}
$$

where $\mathrm{C}$ is the concentration of $\mathrm{NaOH}(\mathrm{mol} / \mathrm{L}), \mathrm{V}$ refers to the consumed volume of $\mathrm{NaOH}(\mathrm{mL})$, and $\mathrm{W}$ represents the quality of the sample $(\mathrm{g})$. The molecular weight of the disaccharide unit is 385, and that of MAH group is 98.

\subsection{Characterization of $M C$ \\ 3.4.1. FT-IR}

The FT-IR spectrum of $k$ Car power was determined on a Nicolet iS50 FT-IR spectrometer (Thermo Fisher Nicolet, Waltham, MA, USA) at room temperature. Prior to pellet preparation, the samples were dried at $55{ }^{\circ} \mathrm{C}$ for $12 \mathrm{~h}$ to remove any moisture, finely ground with $\mathrm{KBr}$ in a ratio of 1:100 $(w / w)$ to generate a thin pellet, and scanned within the wavenumber range of $400-4000 \mathrm{~cm}^{-1}$.

\subsubsection{TGA}

TGA of $\kappa$ Car power was conducted with a thermogravimetric analyzer (TA, Q500, New Castle, DE, USA) between $30{ }^{\circ} \mathrm{C}$ and $600{ }^{\circ} \mathrm{C}$ at a heating rate of $10{ }^{\circ} \mathrm{C} / \mathrm{min}$ in a $\mathrm{N}_{2}$ atmosphere.

\subsection{Determination of Physical Properties}

Gel strength was determined using the method described by Lee et al. [50]. In brief, $100 \mathrm{~mL}$ of hot $\mathrm{KCar}$ solution dissolved in $1.5 \%(w / v)$ water containing $0.2 \mathrm{~g}$ of $\mathrm{KCl}$ was poured into a Petri dish with $30 \mathrm{~mm}$ diameter and 21-22 $\mathrm{mm}$ depth and then allowed to gel at room temperature for $15 \mathrm{~h}$. Gel strength was measured by the load $\left(\mathrm{g} / \mathrm{cm}^{2}\right)$ causing a cylindrical plunger $\left(1 \mathrm{~cm}^{2}\right.$ cross-section $)$ to suddenly break the gel.

The viscosity of $\mathrm{KCar}$ solution at $75{ }^{\circ} \mathrm{C}$ was determined using a Brookfield DV-C Viscometer operating at $50 \mathrm{rpm}$ with spindle \#62. (Brookfield, Middleboro, MA, USA). In brief, $1.5 \%(w / v)$ KCar solution (in distilled water) was prepared by boiling in a microwave oven for $8 \mathrm{~min}$. The hot solution was then placed in a $75^{\circ} \mathrm{C}$ water bath pot insulated for $30 \mathrm{~min}$ [51]. Apparent viscosity was measured using a Brookfield Synchrolectric Viscometer (USA) as described by Zhao et al. [52].

Another $1.5 \% \mathrm{k}$ Car solution $(30 \mathrm{~mL})$ was prepared and poured into a $50 \mathrm{~mL}$ centrifuge tube to determine the water holding capacity. The gel was placed in a freezer for $2 \mathrm{~h}$ and frozen for $8 \mathrm{~h}$ before defrosting. Pressure dehydration with weight was conducted, and the water was poured out. Volume and dehydration rate were calculated $(\mathrm{V} / 30 \times 100)$.

Transparency was measured by transmittance (\%) at $700 \mathrm{~nm}$ with distilled water as blank. The sample solution $(1.5 \%, w / v)$ was placed in the colorimetric ware and then incubated at room temperature for $12 \mathrm{~h}$ [53].

Whiteness was determined using a colorimeter in ADC1-WS1.

The gelling and gel melting temperature of $\mathrm{k} C$ ar were measured at shear deformation by using the TA instrument TRIOS rheometer and the modified method of Derkach et al. [54]. Temperature scanning was performed from $20^{\circ} \mathrm{C}$ to $80^{\circ} \mathrm{C}$, followed by $80^{\circ} \mathrm{C}$ to $20^{\circ} \mathrm{C}$ at a 
scan rate of $2{ }^{\circ} \mathrm{C} / \mathrm{min}$, an amplitude of deformation $\gamma=1 \%$, and a frequency $\omega=6.28 \mathrm{c}^{-1}$. The diameter of the cone was $40 \mathrm{~mm}$, the angle between the cone and plate was $1 \mathrm{grad}$, and the gap between the cone top and the plate was $0.1 \mathrm{~mm}$.

Dissolving temperature was measured by preparing a $10 \mathrm{~mL}$ solution of $\mathrm{\kappa}$ Car glue $(1.0 \%)$ in a test tube in a water bath, and the temperature was increased from $60{ }^{\circ} \mathrm{C}$ to $100{ }^{\circ} \mathrm{C}$ at $1^{\circ} \mathrm{C} / 10 \mathrm{~min}$. The dissolving temperature was recorded when the $\mathrm{kCar}$ powder was completely dissolved [55].

\subsection{Determination of Chemical Compositions}

The sulfate content of $\kappa$ Car was assessed by the barium chloride gelatin method with $\mathrm{K}_{2} \mathrm{SO}_{4}$ as the standard [51], and 3,6-AG content was determined colorimetrically using the resorcinol-acetal method of Freile-Pelegrín and Robledo [56].

\subsection{Preparation of NC/MC Films}

Solution casting was used to prepare the films [57]. In brief, $3.0 \mathrm{~g}$ of NC/MC powder was placed in a beaker and added with $150 \mathrm{~mL}$ of distilled water to reach the mass fraction $2 \%$. The beaker was placed on a magnetic stirrer at $80{ }^{\circ} \mathrm{C}$ and stirred for $30 \mathrm{~min}$ to complete dissolution. The carrageenan solution was added with $0.9 \mathrm{~g}$ of glycerin $(30 \mathrm{wt} \%$ of carrageenan), magnetically stirred at $80{ }^{\circ} \mathrm{C}$ for $30 \mathrm{~min}$ to evenly mix the evaporated water with hot water, and sealed with plastic wrap. The beaker was placed in a constant temperature water bath at $75{ }^{\circ} \mathrm{C}$ for $1 \mathrm{~h}$ to stabilize the carrageenan solution and eliminate bubbles. Afterward, $10.0 \mathrm{~g}$ of the mixed solution was isolated, poured into a glass Petri dish (90 $\mathrm{mm}$ in diameter), and cooled down naturally at room temperature to form a gel. The gel was placed in a $55^{\circ} \mathrm{C}$ blast drying oven for $24 \mathrm{~h}$. The dried films were peeled off from the glass Petri dishes and conditioned in a humidity chamber controlled at $25^{\circ} \mathrm{C}$ and $50 \%$ relative humidity $(\mathrm{RH})$ for at least 2 days before further analysis.

\subsection{Surface Morphology and Cross-Section of NC and MC Films}

The microstructures of surface and cross-section (cryofractured) of NC and MC films were obtained using scanning electron microscopy (S-4800, Hitachi Co., Tokyo, Japan) with an acceleration voltage of $5 \mathrm{kV}$. All of the samples were coated with platinum using a vacuum sputter coater before measurement.

\subsection{Performance Measurement for NC and MC Films \\ 3.9.1. Thickness Measurement}

A micrometer (Thickness Gauge; Mitutoyo Co., Tokyo, Japan) was used to randomly select 10 points (including the center point) on the film to be tested to measure its thickness, and the average value was taken as the film thickness.

\subsubsection{Determination of Optical Properties}

The surface color of NC and MC films was evaluated using a colorimeter (WSC-S; Shanghai Precision \& Scientific Instrument Co., China). A white color plate $\left(L^{*}=91.86\right.$, $a^{*}=-0.88, b^{*}=1.42$ ) was employed as a standard background color. Color parameters such as Hunter $L, a$, and $b$ (L: lightness, $a$ : greenness-redness, and $b$ : blueness-yellowness) values were determined by measuring at the five random points of each film sample. The total color difference $(\Delta E)$ of the film was calculated as follows:

$$
\Delta E=\sqrt{\left(L-L^{*}\right)^{2}+\left(a-a^{*}\right)^{2}+\left(b-b^{*}\right)^{2}}
$$

where $L, a$, and $b$ are the color values of the NC and MC films, respectively.

Film light transmission was measured by transmittance (\%) with the aid of a UVvisible spectrophotometer (Cary-60, Agilent, Santa Clara, CA, USA) operating in the wavelength range of 200-800 $\mathrm{nm}$ with an accuracy of $1 \mathrm{~nm}$. Three replicates of each film were tested. 


\subsubsection{Determination of Mechanical Properties}

Rectangles of $45 \times 20 \mathrm{~mm}$ were cut from the film, and the mechanical properties of $\mathrm{NC} / \mathrm{MC}$ films were measured by a texture analyzer (TMS-PRO, Food Technology Co., Sterling, VA, USA). The test speed was $1 \mathrm{~mm} / \mathrm{s}$, and the initial clamping distance was $30 \mathrm{~mm}$ [58]. Six parallels were measured for each sample, and the average value was taken. The mechanical properties of carrageenan films were calculated according to the following formulas:

$$
\mathrm{TS}=F_{\max } / S
$$

where TS is tensile strength, MPa; $F_{\max }$ is the maximum load when the film is broken, $\mathrm{N}$; and $S$ is the cross-sectional area of membrane, $\mathrm{mm}^{2}$.

$$
\mathrm{EB}=\left(l-l_{0}\right) / l_{0} \times 100
$$

where EB is the elongation at break, $\%$; $l$ is the length of the film after stretching, $\mathrm{mm}$; and $l_{0}$ is the initial length of the film, $\mathrm{mm}$.

\subsubsection{Determination of Water Affinity Properties}

Water contact angle was determined using a contact angle meter (CA-100C; Shanghai Innuo precision instruments Co., Shanghai, China). For each measurement, $5 \mu \mathrm{L}$ of deionized water was dropped onto film surface. Contact angle dynamics with time was measured over $2 \mathrm{~min}$ and plotted as curves.

Film moisture content was analyzed by gravimetry in triplicate by drying the samples at $105{ }^{\circ} \mathrm{C}$ for $24 \mathrm{~h} \mathrm{[59].}$

Water vapor permeability was determined following the standard method of ASTM E96-95 with modification [60]. Film samples were tightened on the top of weighing cups containing $30.00 \mathrm{~g}$ of silica gel. These weighing cups were stored in a specific environment set at $25^{\circ} \mathrm{C}$ and $50 \% \mathrm{RH}$. Weight loss from each cup was measured every $12 \mathrm{~h}$ for 7 days. WVP $(\mathrm{g} / \mathrm{m} \cdot \mathrm{s} \cdot \mathrm{Pa})$ was determined from the slope of the plot of weight change of the cup versus time and calculated as follows:

$$
\mathrm{WVP}=(\Delta m \times X) /(S \times \Delta t \times \Delta p)
$$

where $\Delta m(\mathrm{~g})$ represents the weight change of the weighing cup after 7 days; $X(\mathrm{~m})$ and $S$ $\left(\mathrm{m}^{2}\right)$ are the thickness and area of the film, respectively; $\Delta t$ (s) denotes the time intervals; and $\Delta p(\mathrm{~Pa})$ is the partial water vapor pressure difference across the two sides of the film.

\subsection{Statistical Analysis}

All experimental data were processed by using SPSS (v18.0; SPSS Inc., Chicago, IL, USA). Differences among the average values were obtained via $\mathrm{q}$ test or paired-samples $t$ test $(p<0.05)$.

\section{Conclusions}

KCar was successfully modified by MAH. The maximum DS and minimum gel strength were reached under the following optimal reaction conditions: $30{ }^{\circ} \mathrm{C}$ reaction temperature, $3.5 \mathrm{~h}$ reaction time, $8 \% \mathrm{MAH}$ concentration, $7.5 \% \mathrm{kCar}$ concentration, and $\mathrm{pH}$ 8-8.5. FT-IR spectroscopy showed that characteristic absorptions in MC occurred on the ester carbonyl groups at $1734 \mathrm{~cm}^{-1}$ and the carboxylate at $1576 \mathrm{~cm}^{-1}$. TGA results revealed that the thermal stability of $\mathrm{MC}$ decreased. The physicochemical properties of MC including gelling temperature, gel strength, viscosity, and 3,6-AG content were all decreased, whereas its water holding capacity and transparency were remarkably improved. The increase in MC transparency (from 81.9\% to 91.6\%) favored the color and transparency of MC films. The SEM indicated that the surface of the MC films had become rougher after modification. Moreover, the introduction of MAH groups into $\mathrm{kCar}$ through modification endowed the film with enhanced hydrophobicity and ability to absorb UV light in the 
range of 200-236 $\mathrm{nm}$. The reduced intermolecular forces of $\mathrm{\kappa Car}$ also led to a substantial increase in EB from $26.9 \%$ to $163 \%$. Therefore, the novel MC with MAH could be effectively exploited in polysaccharide-based films.

Author Contributions: Conceptualization, Y.Z., F.-Q.C., S.C. and A.-F.X.; methodology, Q.X. and H.-F.W.; investigation, Y.Z. and S.C.; resources, Q.-M.Y. and H.-F.W.; writing-original draft preparation, Y.Z. and S.C.; writing-review and editing, Y.Z., F.-Q.C. and A.-F.X.; visualization, Y.Z., F.-Q.C. and Q.X.; supervision, A.-F.X.; project administration, A.-F.X.; funding acquisition, Q.X. and A.-F.X. All authors have read and agreed to the published version of the manuscript.

Funding: This work was supported by the Major Science and Technology Programs and Special Topics of Fujian Province (2020NZ012013), Startup Research Fund of Jimei University (Z92143), Middle-aged and Young Teachers' Science and Technology Project of Fujian Education Department (C521079), and the Fujian Province Natural Science Foundation of China (2019J01701, 2020J01680).

Institutional Review Board Statement: Not applicable.

Informed Consent Statement: Not applicable.

Data Availability Statement: Data are contained within the article.

Conflicts of Interest: The authors declare no competing financial interest.

\section{References}

1. Campo, V.L.; Kawano, D.F.; Silva, D.B.d.; Carvalho, I. Carrageenans: Biological properties, chemical modifications and structural analysis-A review. Carbohydr. Polym. 2009, 77, 167-180. [CrossRef]

2. Torres, M.D.; Chenlo, F.; Moreira, R. Structural features and water sorption isotherms of carrageenans: A prediction model for hybrid carrageenans. Carbohydr. Polym. 2018, 180, 72-80. [CrossRef]

3. Torres, M.D.; Florez-Fernandez, N.; Dominguez, H. Integral Utilization of Red Seaweed for Bioactive Production. Mar. Drugs 2019, 17, 314. [CrossRef]

4. Zia, K.M.; Tabasum, S.; Nasif, M.; Sultan, N.; Aslam, N.; Noreen, A.; Zuber, M. A review on synthesis, properties and applications of natural polymer based carrageenan blends and composites. Int. J. Biol. Macromol. 2017, 96, 282-301. [CrossRef]

5. Fan, L.; Wang, L.; Gao, S.; Wu, P.; Li, M.; Xie, W.; Liu, S.; Wang, W. Synthesis, characterization and properties of carboxymethyl kappa carrageenan. Carbohydr. Polym. 2011, 86, 1167-1174. [CrossRef]

6. Sinthusamran, S.; Benjakul, S.; Swedlund, P.J.; Hemar, Y. Physical and rheological properties of fish gelatin gel as influenced by k-carrageenan. Food Biosci. 2017, 20, 88-95. [CrossRef]

7. Savoji, M.T.; Pourjavadi, A. Partially hydrolyzed kappa carrageenan-Polyacrylonitrile as a novel biopolymer-based superabsorbent hydrogel: Synthesis, characterization, and swelling behaviors. Polym. Eng. Sci. 2006, 46, 1778-1786. [CrossRef]

8. Papageorgiou, M.; Nanaki, S.G.; Kyzas, G.Z.; Koulouktsi, C.; Bikiaris, D.N.; Lambropoulou, D.A. Novel Isocyanate-Modified Carrageenan Polymer Materials: Preparation, Characterization and Application Adsorbent Materials of Pharmaceuticals. Polymers 2017, 9, 595. [CrossRef]

9. Marshall, P.; Papadimitriou, V.C.; Papanastasiou, D.K.; Roberts, J.M.; Burkholder, J.B. UV and infrared absorption spectra and 248 nm photolysis of maleic anhydride $\left(\mathrm{C}_{4} \mathrm{H}_{2} \mathrm{O}_{3}\right)$. J. Photochem. Photobiol. 2019, 382, 111953. [CrossRef]

10. Zuo, Y.; Gu, J.; Yang, L.; Qiao, Z.; Tan, H.; Zhang, Y. Synthesis and characterization of maleic anhydride esterified corn starch by the dry method. Int. J. Biol. Macromol. 2013, 62, 241-247. [CrossRef]

11. Jiang, Y.-P.; Guo, X.-K.; Tian, X.-F. Synthesis and NMR structural analysis of O-succinyl derivative of low-molecular-weight K-carrageenan. Carbohydr. Polym. 2005, 61, 399-406. [CrossRef]

12. Sumathra, M.; Rajan, M.; Amarnath Praphakar, R.; Marraiki, N.; Elgorban, A.M. In Vivo Assessment of a Hydroxyapatite/kappaCarrageenan-Maleic Anhydride-Casein/Doxorubicin Composite-Coated Titanium Bone Implant. ACS Biomater. Sci. Eng. 2020, 6, 1650-1662. [CrossRef] [PubMed]

13. Rees, D.A. Structure, Conformation, and Mechanism in the Formation of Polysaccharide Gels and Networks. Adv.Carbohydr. Chem. Biochem. 1969, 24, 267-332. [PubMed]

14. Gunaratne, A.; Corke, H. Influence of unmodified and modified cycloheptaamylose ( $\beta$-cyclodextrin) on transition parameters of amylose-lipid complex and functional properties of starch. Carbohydr. Polym. 2007, 68, 226-234. [CrossRef]

15. Bello-Pérez, L.A.; Sánchez-Rivera, M.M.; Núñez-Santiago, C.; Rodríguez-Ambriz, S.L.; Román-Gutierrez, A.D. Effect of the pearled in the isolation and the morphological, physicochemical and rheological characteristics of barley starch. Carbohydr. Polym. 2010, 81, 63-69. [CrossRef]

16. Xiao, Q.; Weng, H.; Chen, G.; Xiao, A. Preparation and characterization of octenyl succinic anhydride modified agarose derivative. Food Chem. 2019, 279, 30-39. [CrossRef] [PubMed] 
17. de Lima Barizao, C.; Crepaldi, M.I.; Junior, O.O.S.; de Oliveira, A.C.; Martins, A.F.; Garcia, P.S.; Bonafe, E.G. Biodegradable films based on commercial kappa-carrageenan and cassava starch to achieve low production costs. Int. J. Biol. Macromol. 2020, 165, 582-590. [CrossRef]

18. Duan, N.; Li, Q.; Meng, X.; Wang, Z.; Wu, S. Preparation and characterization of k-carrageenan $/ \mathrm{konjac}_{\text {glucomannan } / \mathrm{TiO}} 2$ nanocomposite film with efficient anti-fungal activity and its application in strawberry preservation. Food Chem. 2021, 364, 130441. [CrossRef]

19. Sedayu, B.B.; Cran, M.J.; Bigger, S.W. A Review of Property Enhancement Techniques for Carrageenan-based Films and Coatings. Carbohydr. Polym. 2019, 216, 287-302. [CrossRef]

20. Shahbazi, M.; Majzoobi, M.; Farahnaky, A. Physical modification of starch by high-pressure homogenization for improving functional properties of $\mathrm{k}$-carrageenan/starch blend film. Food Hydrocolloid. 2018, 85, 204-214. [CrossRef]

21. Saedi, S.; Rhim, J.-W. Synthesis of $\mathrm{Fe}_{3} \mathrm{O}_{4} @ \mathrm{SiO}_{2} @ P A M A M$ dendrimer@AgNP hybrid nanoparticles for the preparation of carrageenan-based functional nanocomposite film. Food Packag. Shelf. 2020, 24, 100473. [CrossRef]

22. Zhuikova, Y.V.; Zhuikov, V.A.; Zubareva, A.A.; Akhmedova, S.A.; Sviridova, I.K.; Sergeeva, N.S.; Varlamov, V.P. Physicochemical and biological characteristics of chitosan/kappa-carrageenan thin layer-by-layer films for surface modification of nitinol. Micron. Technol. 2020, 138, 102922. [CrossRef]

23. Hernández-Moreno, D.; de la Casa Resino, I.; Soler-Rodríguez, F. Maleic Anhydride. In Encyclopedia of Toxicology, 3rd ed.; Philip, W., Ed.; US National Library of Medicine: Bethesda, MD, USA, 2014; pp. 138-141.

24. Moad, G. Chemical modification of starch by reactive extrusion. Prog. Polym. Sci. 2011, 36, 218-237. [CrossRef]

25. Pongsawatmanit, R.; Srijunthongsiri, S. Influence of xanthan gum on rheological properties and freeze-thaw stability of tapioca starch. J. Food Eng. 2008, 88, 137-143. [CrossRef]

26. Maity, T.; Saxena, A.; Raju, P.S. Use of hydrocolloids as cryoprotectant for frozen foods. Crit. Rev. Food. Sci. Nutr. 2018, 58, 420-435. [CrossRef]

27. Bao, J.; Xing, J.; Phillips, D.L.; Corke, H. Physical Properties of Octenyl Succinic Anhydride Modified Rice, Wheat, and Potato Starches. J. Agric. Food Chem. 2003, 51, 2283-2287. [CrossRef]

28. Abiddin, N.; Yusoff, A.; Ahmad, N. Effect of octenylsuccinylation on physicochemical, thermal, morphological and stability of octenyl succinic anhydride (OSA) modified sago starch. Food Hydrocolloid. 2017, 75, 138-146. [CrossRef]

29. Bartz, J.; Goebel, J.T.; Giovanaz, M.A.; Zavareze Eda, R.; Schirmer, M.A.; Dias, A.R. Acetylation of barnyardgrass starch with acetic anhydride under iodine catalysis. Food Chem. 2015, 178, 236-242. [CrossRef]

30. Ruan, H.; Chen, Q.H.; Fu, M.L.; Xu, Q.; He, G.Q. Preparation and properties of octenyl succinic anhydride modified potato starch. Food Chem. 2009, 114, 81-86.

31. Simsek, S.; Ovando-Martinez, M.; Marefati, A.; Sj, M.; Rayner, M. Chemical composition, digestibility and emulsification properties of octenyl succinic esters of various starches. Food Res. Int. 2015, 75, 41-49. [CrossRef]

32. Chen, H.; Chen, F.; Xiao, Q.; Cai, M.; Yang, Q.; Weng, H.; Xiao, A. Structure and physicochemical properties of amphiphilic agar modified with octenyl succinic anhydride. Carbohydr. Polym. 2021, 251, 117031. [CrossRef]

33. Quintero-Castano, V.D.; Castellanos-Galeano, F.J.; Alvarez-Barreto, C.I.; Lucas-Aguirre, J.C.; Bello-Perez, L.A.; Rodriguez-Garcia, M.E. Starch from two unripe plantains and esterified with octenyl succinic anhydride (OSA): Partial characterization. Food Chem. 2020, 315, 126241. [CrossRef]

34. Wongprasert, K.; Rudtanatip, T.; Praiboon, J. Immunostimulatory activity of sulfated galactans isolated from the red seaweed Gracilaria fisheri and development of resistance against white spot syndrome virus (WSSV) in shrimp. Fish Shellfish. Immunol. 2014, 36, 52-60. [CrossRef]

35. Pettinelli, N.; Rodriguez-Llamazares, S.; Abella, V.; Barral, L.; Bouza, R.; Farrag, Y.; Lago, F. Entrapment of chitosan, pectin or kappa-carrageenan within methacrylate based hydrogels: Effect on swelling and mechanical properties. Mat. Sci. Eng. C-Mater. 2019, 96, 583-590. [CrossRef]

36. Meindrawan, B.; Suyatma, N.E.; Wardana, A.A.; Pamela, V.Y. Nanocomposite coating based on carrageenan and ZnO nanoparticles to maintain the storage quality of mango. Food Packag. Shelf. 2018, 18, 140-146. [CrossRef]

37. Normand, V. Effect of sucrose on agarose gels mechanical behaviour. Carbohydr. Polym. 2003, 54, 83-95. [CrossRef]

38. Sanchez-Rivera, M.M.; Almanza-Benitez, S.; Bello-Perez, L.A.; Mendez-Montealvo, G.; Nunez-Santiago, M.C.; Rodriguez-Ambriz, S.L.; Gutierrez-Meraz, F. Acetylation of banana (Musa paradisiaca L.) and corn (Zea mays L.) starches using a microwave heating procedure and iodine as catalyst: II. Rheological and structural studies. Carbohydr. Polym. 2013, 92, 1256-1261. [CrossRef]

39. Ruiter, G.; Rudolph, B. Carrageenan biotechnology. Trends Food Sci. Technol. 1997, 8, 389-395. [CrossRef]

40. Bhosale, R.; Singhal, R. Effect of octenylsuccinylation on physicochemical and functional properties of waxy maize and amaranth starches. Carbohydr. Polym. 2007, 68, 447-456. [CrossRef]

41. Duckworth, M.; Yaphe, W. The structure of agar: Part I. Fractionation of a complex mixture of polysaccharides. Carbohydr. Res. 1971, 16, 189-197. [CrossRef]

42. Li, J.; Ye, F.; Liu, J.; Zhao, G. Effects of octenylsuccination on physical, mechanical and moisture-proof properties of stretchable sweet potato starch film. Food Hydrocolloid. 2015, 46, 226-232. [CrossRef]

43. Cazon, P.; Vazquez, M.; Velazquez, G. Cellulose-glycerol-polyvinyl alcohol composite films for food packaging: Evaluation of water adsorption, mechanical properties, light-barrier properties and transparency. Carbohydr. Polym. 2018, 195, 432-443. [CrossRef] [PubMed] 
44. Ochoa, T.A.; Almendárez, B.E.G.; Reyes, A.A.; Pastrana, D.M.R.; López, G.F.G.; Belloso, O.M.; González, C.R. Design and Characterization of Corn Starch Edible Films Including Beeswax and Natural Antimicrobials. Food Bioprocess Technol. 2016, 10, 103-114. [CrossRef]

45. Lu, J.; Fang, J.; Li, J.; Zhu, L. Engineering highly transparent UV-shielding films with disassembled polydopamine oligomers as light adsorber. Appl. Sur. Sci. 2021, 550, 149284. [CrossRef]

46. Omar-Aziz, M.; Khodaiyan, F.; Yarmand, M.S.; Mousavi, M.; Gharaghani, M.; Kennedy, J.F.; Hosseini, S.S. Combined effects of octenylsuccination and beeswax on pullulan films: Water-resistant and mechanical properties. Carbohydr. Polym. 2021, 255, 117471. [CrossRef]

47. Gahruie, H.H.; Eskandari, M.H.; Van der Meeren, P.; Hosseini, S.M.H. Study on hydrophobic modification of basil seed gum-based (BSG) films by octenyl succinate anhydride (OSA). Carbohydr. Polym. 2019, 219, 155-161. [CrossRef] [PubMed]

48. Zhang, B.; Huang, Q.; Luo, F.-x.; Fu, X.; Jiang, H.; Jane, J.-l. Effects of octenylsuccinylation on the structure and properties of high-amylose maize starch. Carbohydr. Polym. 2011, 84, 1276-1281. [CrossRef]

49. Li, Y.T.; Wang, R.S.; Liang, R.H.; Chen, J.; He, X.H.; Chen, R.Y.; Liu, W.; Liu, C.M. Dynamic high-pressure microfluidization assisting octenyl succinic anhydride modification of rice starch. Carbohydr. Polym. 2018, 193, 336-342. [CrossRef] [PubMed]

50. Lee, W.-K.; Lim, P.-E.; Phang, S.-M.; Namasivayam, P.; Ho, C.-L. Agar properties of Gracilaria species (Gracilariaceae, Rhodophyta) collected from different natural habitats in Malaysia. Reg. Stud. Mar. Sci. 2016, 7, 123-128. [CrossRef]

51. Yarnpakdee, S.; Benjakul, S.; Kingwascharapong, P. Physico-chemical and gel properties of agar from Gracilaria tenuistipitata from the lake of Songkhla, Thailand. Food Hydrocolloid. 2015, 51, 217-226. [CrossRef]

52. Zhao, J.; Sun, C.; Li, H.; Dong, X.; Zhang, X. Studies on the physicochemical properties, gelling behavior and drug release performance of agar/kappa-carrageenan mixed hydrogels. Int. J. Biol. Macromol. 2020, 154, 878-887. [CrossRef]

53. An, D.; Xiao, Q.; Zhang, C.; Cai, M.; Zhang, Y.; Weng, H.; Chen, F.; Xiao, A. Preparation, characterization, and application of high-whiteness agar bleached with hydrogen peroxide. Food Hydrocolloid. 2021, 113, 106520. [CrossRef]

54. Derkach, S.R.; Voron'ko, N.G.; Kuchina, Y.A.; Kolotova, D.S.; Gordeeva, A.M.; Faizullin, D.A.; Gusev, Y.A.; Zuev, Y.F.; Makshakova, O.N. Molecular structure and properties of kappa-carrageenan-gelatin gels. Carbohydr. Polym. 2018, 197, 66-74. [CrossRef] [PubMed]

55. Cao, M.; Liu, X.; Luan, J.; Zhang, X. Characterization of physicochemical properties of carboxymethyl agar. Carbohydr. Polym. 2014, 111, 449-455. [CrossRef]

56. Freile-Pelegrín, Y.; Robledo, D. Influence of alkali treatment on agar from Gracilaria cornea from Yucatán, México. J. Appl. Phycol. 1997, 9, 533.

57. Saedi, S.; Shokri, M.; Roy, S.; Rhim, J.-W. Silver loaded aminosilane modified halloysite for the preparation of carrageenan-based functional films. Appl. Clay Sci. 2021, 211, 106170. [CrossRef]

58. Chen, S.; Tang, L.; Hao, G.; Weng, W.; Osako, K.; Tanaka, M. Effects of $\alpha 1 / \alpha 2$ ratios and drying temperatures on the properties of gelatin films prepared from tilapia (Tilapia zillii) skins. Food Hydrocolloid. 2016, 52, 573-580. [CrossRef]

59. Garrido, T.; Etxabide, A.; Guerrero, P.; de la Caba, K. Characterization of agar/soy protein biocomposite films: Effect of agar on the extruded pellets and compression moulded films. Carbohydr. Polym. 2016, 151, 408-416. [CrossRef]

60. Gennadios, A.; Brandenburg, A.H.; Park, J.W.; Weller, C.L.; Testin, R.F. Water vapor permeability of wheat gluten and soy protein isolate films. Ind. Crop. Prod. 1994, 2, 189-195. [CrossRef] 